\title{
Numerical modelling of coupled heat, air and moisture transfer in building envelopes
}

\author{
Mustapha Maliki $^{1, a}$, Nadia Laredj ${ }^{1}$, Hanifi Missoum ${ }^{1}$, Karim Bendani $^{1}$ \\ AND HASSAN NAJI ${ }^{2,3}$ \\ 1 LCTPE Laboratory, Faculty of Science and Technology, University Abdelhamid Ibn Badis, 27000 Mostaganem, Algeria \\ 2 Université Lille Nord de France, 59000 Lille, France \\ 3 Laboratoire Génie Civil \& Géo-Environnement (LGCgE- EA 4515), Université d'Artois/FSA Béthune, 62400 Béthune, France
}

Received 26 March 2014, Accepted 30 December 2014

\begin{abstract}
This paper reports on numerical modeling of heat, air, and moisture transfer through multilayered walls. Building materials are often subjected to temporal climatic variations, which can induce a transfer of heat and moisture through the walls of the building and the foundation soil. These materials are generally considered as porous media. The coupled heat, air and moisture transfer in building materials is of paramount importance in the construction area. In this way, a mathematical model has been elaborated and validated using a benchmark example. Here, we aim to determine the energy losses. The capillary pressure is considered as potential moisture which represents both the transport of vapor and liquid phases of the water. Basing on basic functions of partial differential equations (PDE's), one can convert certain measurable properties of porous media as coefficients depending on the temperature and the capillary pressure. The results obtained compare favourably with other available in the literature.
\end{abstract}

Key words: Coupled transfer / heat / moisture / porous media / simulation

\section{Introduction}

Energy consumption by the building sector constitutes a large portion of global energy use. Energy-efficient building technologies help to reduce heat gain in hot summer months, heat loss in cold winter months, and modify energy requirements in buildings [1]. The moisture transferring in building materials can cause serious results as metal corrosion, structure deterioration and decreasing performance of building insulations. Also, the expansion and deformation of building envelope framework during freezing process have an important impact on building durability and energy consumption in the cold regions. So the study on heat and moisture transfer of building envelope is of great important.

Several studies have pointed out the advantages of using renewable materials in the context of energy saving issues. However, in these materials both thermal and hygroscopic transport must be considered to accurately predict the energetic behavior and the overall comfort of the building. In most recent insulation technologies the wall itself is made of several different material layers. For these envelopes, the heat transfer, moisture transfer

\footnotetext{
${ }^{a}$ Corresponding author: mus27000@yahoo.fr
}

and air infiltration are a typical heat and mass coupled transfer process [2]. An accurate coupled heat, air, and moisture transfer (HAM) through porous media is of special interest in many engineering areas such as pollutants infiltration, drying in porous solids and soils, drying of woods and papers, soil mechanics, building thermal insulation, and etc. In this sense, see References [3-6] to name a few. The air infiltration through the permeable building elements is of paramount importance in the construction area. It is an important factor, which can considerably affect their hygrothermal performance. The moisture effects are even more important because the air flow is able to transport high amounts of water vapor into the elements and subsequently cause interstitial condensation with very high condensation rate. This can even lead to serious damage of such permeable and/or leaky constructions. In addition, moisture accumulation within the material of a building envelop can lead to poor thermal performance of the envelope, degradation of organic materials and structure deterioration. Therefore, in the construction area, detailed heat, air and moisture models are needed to increase the accuracy of heat and moisture transfer calculation between outdoor and indoor environments for better predicting thermal loads, indoor thermal comfort and air quality indices and mold growth risk. 


\section{Nomenclature}

\begin{tabular}{|c|c|}
\hline \multicolumn{2}{|r|}{ Latin symbols } \\
\hline$c_{\mathrm{P}, \mathrm{m}}$ & Dry specific heat of material $\left(\right.$ J.K $\left.{ }^{-1} \cdot \mathrm{kg}^{-1}\right)$ \\
\hline$c_{\mathrm{P}, \mathrm{a}}$ & Specific heat of dry air $\left(\mathrm{J} . \mathrm{K}^{-1} \cdot \mathrm{kg}^{-1}\right)$ \\
\hline$c_{\mathrm{P}, 1}$ & Specific heat of liquid water $\left(\mathrm{J} . \mathrm{K}^{-1} \cdot \mathrm{kg}^{-1}\right)$ \\
\hline$F_{\mathrm{h}}$ & Heat source term $\left(\mathrm{W} \cdot \mathrm{m}^{-3}\right)$ \\
\hline$F_{\mathrm{m}}$ & Moisture source term $\left(\mathrm{Kg} \cdot \mathrm{m}^{-3} \cdot \mathrm{s}^{-1}\right)$ \\
\hline$g$ & Acceleration due to gravity $\left(\mathrm{m} \cdot \mathrm{s}^{-2}\right)$ \\
\hline$g_{\mathrm{n}, \mathrm{e}}$ & Outside moisture flux $\left(\mathrm{kg} \cdot \mathrm{m}^{-2} \cdot \mathrm{s}^{-1}\right)$ \\
\hline$g_{\mathrm{n}, \mathrm{i}}$ & Interior moisture flux $\left(\mathrm{kg} \cdot \mathrm{m}^{-2} \cdot \mathrm{s}^{-1}\right)$ \\
\hline$g_{\mathrm{wdr}}$ & Moisture supply due to wind-driven rain $\left(\mathrm{kg} \cdot \mathrm{m}^{-2} \cdot \mathrm{s}^{-1}\right)$ \\
\hline$k_{\mathrm{a}}$ & Air permeability of material $\left(\mathrm{kg} \cdot \mathrm{m}^{-1}\right.$.s.Pa) \\
\hline$K_{1}$ & Liquid water permeability (s) \\
\hline$L_{\mathrm{V}}$ & Evaporation's enthalpy $\left(\mathrm{J} \mathrm{kg}^{-1}\right)$ \\
\hline$p_{\mathrm{a}}$ & Dry air pressure $(\mathrm{Pa})$ \\
\hline$p_{\mathrm{V}}$ & Partial water vapor pressure $(\mathrm{Pa})$ \\
\hline$p_{\mathrm{C}}$ & Capillary pressure $(\mathrm{Pa})$ \\
\hline$p_{\text {sat }}$ & Saturated water vapor pressure $(\mathrm{Pa})$ \\
\hline$p_{\text {atm }}$ & Atmospheric pressure $(\mathrm{Pa})$ \\
\hline$q_{\mathrm{n}, \mathrm{i}}$ & Heat flux through internal surface of the building envelope $\left(\mathrm{W} \cdot \mathrm{m}^{-2}\right)$ \\
\hline$t$ & Time (s) \\
\hline$T$ & Temperature $(\mathrm{K})$ \\
\hline$v$ & Air velocity $\left(\mathrm{m} . \mathrm{s}^{-1}\right)$ \\
\hline$w$ & Moisture content $\left(\mathrm{kg} \cdot \mathrm{m}^{-3}\right)$ \\
\hline$R_{\mathrm{V}}$ & Gas constant for water vapour $\left(\mathrm{J} . \mathrm{kg}^{-1} \cdot \mathrm{K}^{-1}\right)$ \\
\hline \multicolumn{2}{|r|}{ Greek symbols } \\
\hline$\alpha$ & Heat transfer coefficient $\left(\mathrm{W} \cdot \mathrm{m}^{-2} \cdot \mathrm{K}^{-1}\right)$ \\
\hline$\beta$ & Thermal expansion coefficient of air $\left(\mathrm{K}^{-1}\right)$ \\
\hline$\beta_{\mathrm{P}}$ & Vapor transfer coefficient $\left(\mathrm{kg} \cdot \mathrm{m}^{-2} \cdot \mathrm{s}^{-1} \cdot \mathrm{Pa}^{-1}\right)$ \\
\hline$\delta_{\mathrm{P}}$ & Water vapor permeability $\left(\mathrm{kg} \cdot \mathrm{m}^{-1} \cdot \mathrm{s}^{-1} \cdot \mathrm{Pa}^{-1}\right)$ \\
\hline$\lambda$ & Thermal conductivity $\left(\mathrm{W} \cdot \mathrm{m}^{-1} \cdot \mathrm{K}^{-1}\right)$ \\
\hline$\phi$ & Relative humidity $(-)$ \\
\hline$\mu_{\mathrm{a}}$ & Air dynamic viscosity $\left(\mathrm{kg} \cdot \mathrm{m}^{-1} \cdot \mathrm{s}^{-1}\right)$ \\
\hline$\Omega$ & Moisture storage capacity $\left(\mathrm{kg} \cdot \mathrm{m}^{-3} \cdot \mathrm{Pa}^{-1}\right)$ \\
\hline$\rho_{\mathrm{m}}$ & Dry density of the material $\left(\mathrm{kg} \cdot \mathrm{m}^{-3}\right)$ \\
\hline$\rho_{\mathrm{a}}$ & Dry air density $\left(\mathrm{kg} \cdot \mathrm{m}^{-3}\right)$ \\
\hline$\rho_{1}$ & Water density $\left(\mathrm{kg} \cdot \mathrm{m}^{-3}\right)$ \\
\hline$\rho_{\mathrm{V}}$ & Water vapor density $\left(\mathrm{kg} \cdot \mathrm{m}^{-3}\right)$ \\
\hline \multicolumn{2}{|r|}{ Superscripts/Subscripts } \\
\hline $\mathrm{a}$ & Air \\
\hline dry & Dry condition \\
\hline e & Exterior side of building envelope \\
\hline eq & Equivalent \\
\hline $\mathrm{h}$ & Heat \\
\hline I & Interior side of building envelope \\
\hline 1 & Liquid \\
\hline $\mathrm{m}$ & Medium \\
\hline $\mathrm{n}$ & Normal direction \\
\hline sat & Saturation state \\
\hline surf & Surface \\
\hline $\mathrm{v}$ & Vapor \\
\hline
\end{tabular}

It should be noted that gradients of temperature and vapor pressure can generate temperature and humidity flows inside the building envelope. Besides, thermal characteristics and those related to storage moisture's layers of the wall should be added. This combination makes the transport of heat and moisture transient and relatively complex in the building envelope. Despite this complex- ity, we can numerically simulate the dynamic processes drying-moistening of the building envelope component.

In this context, hygrothermal models have been used to evaluate the performance of a wall exposed to the weather in different geographical sites [7-9]. To describe hygrothermal transfer in capillary porous media, Luikov [9] has leaned on analogy between moisture 
migration and heat transfer to develop and design a model which use the temperature and moisture content as driving potentials. Moreover, he assumed that capillary transport is proportional to moisture content and temperature gradients. Also, by analogy with specific heat, he introduced the specific mass capacity which is defined as the derivative of the water content with respect to the mass potential. This model is applicable for both hygroscopic and non-hygroscopic materials. It has been used by several researchers [10-12]. Among these authors, one can cite (1) Pedersen [13] who used the capillary suction pressure; (2) Künzel and Kiessl [14] who considered the relative humidity; and (3) Mendes and Philippi [7] who showed that gradients of moisture can be used as driving force of heat and computing moisture transport via the interface between porous materials with different pore size distribution functions. The calculation approach used by these authors seems correct since it takes into account such a discontinuity phenomenon at the interface. Always with regard to the heat transfer through the building envelope, there are some aspects that should be handled using complex calculation. These are the phenomenon's multidimensionality, its transient behavior, and moisture conditions.

Several numerical tools have been developed to simulate the transfer of heat, air and moisture in building envelopes. Note that these ones belong to the class of models that have recently emerged to handle the coupled transfer mentioned above. These are implemented either in commercial codes either in house codes to solve problems inherent to buildings physics [15-21]. In this way, Qinru et al. [16] develop a numerical tool to predict combined heat, air and moisture transport in building envelopes, abbreviated as HAM-BE, by making use of commercial finite-element software, COMSOL Multiphysics. The material properties are expressed as analytical or interpolation functions of moisture state variables. Recently, Yanfeng et al. [22] evaluated the internal surface temperature of walls made of different materials, they concluded that when the moisture transfer is taken into account, the internal surface temperature has cooling effect on the indoor air and is beneficial to improve the indoor thermal environment during the working hours in summer. The three transport phenomena (HAM) were coupled and solved simultaneously for temperature, relative humidity and pressure considered as driving potentials by Tariku et al. [23], the performed numerical tool called HAMFIT is an equation-based modeling technique, which requires less time of implementation and provides high degree of transparency and flexibility of modeling, is used for solving the coupled PDEs.

In this paper, a new transient heat, air and moisture transfer model is developed based on basic conservation of mass and energy equations. The governing partial-differential equations (PDEs) of the three transport phenomena are coupled and solved simultaneously for temperature and capillary pressure. The model accommodates non-linear transfer and storage properties of materials, moisture transfer by vapor diffusion, capillary liquid water transport and convective heat and moisture transfer through multi-layered porous media. The PDEs are derived in such a way that each PDE is described with a single driving potential, which is continuous across the interfaces of adjoining materials. The three-coupled transient HAM equations were simultaneously solved using the COMSOL Multiphysics time-dependent solver [24]. The solver is based on an explicit scheme with variable time stepping. The user can predefine the maximum time step so that it matches with the boundary conditions change periods.

\section{Mathematical model}

Physical models that form the basis for various software tools used to predict the heat, air and moisture response of building envelopes seem quite diverse. This section addresses the model for heat and moisture transfer, to be implemented for building materials, adopted here. This is based on the temperature and the capillary pressure as independent variables. Note that in the coupled transfer, the moisture transport in building materials appears under two different phases: liquid and vapor. The vapor phase is divided into diffusion and convection parts. Indeed, the diffusive flow of vapor is engendered by vapor pressure gradient and the corresponding conductivity represents the permeability of the vapor. As for the convective vapor flow, it is advected by the moving air [23].

The modeling of the transfer in vapor phase by the gradient of capillary pressure as conductive potential, and the permeability of the liquid as the conductivity of moisture transfer became the most appropriate approach and the most used one in this kind of modeling [25]. For the liquid flow, moisture content gradient has been used as the driving potential in some hygrothermal tools, and moisture diffusivity was used as the moisture transfer conductivity.

According to the principle of the preservation of the combined transport of heat and humidity of a representative elementary volume (REV), which is defined as being large enough when compared to pore dimensions but small enough compared to the size of the sample, governing equations of the coupled transfer in building materials can be formulated. In order to simulate heat and moisture transfers in multi-layered wall, different kinds of transport equations and boundary conditions are required. Hereafter, these equations are outlined according to the considered medium. These equations require dedicated boundary conditions in order to close the problem and solve the coupled equations. Note that, to characterize the humid air mixture, the assumption of ideal gas was made for dry air and water vapor.

\subsection{Moisture transfer}

It should be noted that the moisture transfer through composite walls, even in a one-dimensional process is a complex phenomenon that involves coupled transfers of 
liquid, vapor and heat. According to Qinru et al. [16], and after some manipulations and conjectures, the governing equation for the moisture content through the medium can be expressed by the following equation

$$
\frac{\partial w}{\partial t}=\nabla\left(\delta_{\mathrm{P}} \nabla p_{\mathrm{V}}-K_{\mathrm{l}} \nabla p_{\mathrm{C}}\right)-v \nabla \rho_{\mathrm{V}}+F_{\mathrm{mo}}
$$

where $w$ is the moisture content, $t$ is the time, $\delta_{\mathrm{P}}$ is the water vapor permeability, $p_{\mathrm{V}}$ is the partial water vapor pressure, $K_{1}$ is the liquid water permeability, $p_{\mathrm{C}}$ is the capillary pressure, $v$ is the air velocity, $\rho_{\mathrm{V}}$ is the water vapor density and $F_{\mathrm{mo}}$ is the moisture source term related to the moisture content.

\subsection{Heat transfer}

Here, we conjecture that the main mechanisms which govern the transfer of heat are the thermal conduction and the convection due to air movement and latent heat. This is due to the presence of low temperature gradients. In this way, the energy conservation equation can be written in terms of a driving potential as follows [26]:

$$
\begin{aligned}
\left(c_{\mathrm{P}, \mathrm{m}} \rho_{\mathrm{m}}+c_{\mathrm{P}, \mathrm{l}} w\right) & \frac{\partial T}{\partial t}=\nabla(\lambda \nabla T)+L_{\mathrm{V}} \nabla\left(\delta_{\mathrm{P}} \nabla p_{\mathrm{V}}\right) \\
& -v\left(L_{\mathrm{V}} \nabla \rho_{\mathrm{V}}+\rho_{\mathrm{a}} c_{\mathrm{P}, \mathrm{a}} \nabla T\right)+F_{\mathrm{h}}
\end{aligned}
$$

where $c_{\mathrm{P}, \mathrm{m}}$ is the dry specific heat of material, $\rho_{\mathrm{m}}$ is the dry density of the material, $c_{\mathrm{P}, 1}$ is the specific heat of liquid water, $T$ is the temperature, $\lambda$ is the thermal conductivity, $L_{\mathrm{V}}$ is the enthalpy of evaporation, $\rho_{\mathrm{a}}$ is the dry air density, $c_{\mathrm{P}, \mathrm{a}}$ is the specific heat of dry air and $F_{\mathrm{h}}$ is the heat source term related to temperature.

\subsection{Conservation equations solving}

As we stated at the beginning, we opted to recast Equations (1) and (2) through a single variable which is the capillary pressure $\left(p_{\mathrm{c}}\right)$. Moreover, the relationship between the partial water vapor pressure and the relative humidity can be expressed as:

$$
p_{\mathrm{V}}=\phi p_{\mathrm{sat}}
$$

where $\phi$ is the relative humidity, and $p_{\text {sat }}$ is the saturated water vapor pressure. Note that the relative humidity is often chosen as a flow potential since it is continuous at the interface of two layers of materials having different moisture storage properties (sorption and moisture retention). Relative humidity is often chosen as a flow potential, since it is continuous at the interface of layers of materials having different moisture storage properties. This potential is linked to the capillary pressure via the following relationship (Kelvin's law):

$$
\phi=\exp \left(\frac{-p_{\mathrm{C}}}{\rho_{\mathrm{l}} R_{\mathrm{V}} T}\right)
$$

where $\rho_{\mathrm{l}}$ is the water density and $R_{\mathrm{V}}$ is the gas constant for water vapour.

It ensures from this that the conservation equations of the combined heat and moisture transfer can be recasted in term of coefficients, and by considering temperature as independent variable for heat transfer and capillary pressure as independent variable for moisture transfer. By following this procedure, the equations can take the following form:

$$
\begin{aligned}
C_{\mathrm{T}} \frac{\partial T}{\partial t}=\nabla & \left(C_{11} \nabla T+C_{12} \nabla p_{\mathrm{C}}\right)+v\left(D_{11} \nabla T+D_{12} \nabla p_{\mathrm{C}}\right) \\
& +F_{\mathrm{h}} \\
\Omega \frac{\partial p_{\mathrm{C}}}{\partial t}=\nabla & \left(C_{21} \nabla T+C_{22} \nabla p_{\mathrm{C}}\right)+v\left(D_{21} \nabla T+D_{22} \nabla p_{\mathrm{C}}\right) \\
& +F_{\mathrm{mo}}
\end{aligned}
$$

where $C_{\mathrm{T}}$ the specific heat of the medium defined as a function of dry air and liquid water heat capacities $\left(C_{\mathrm{T}}=c_{\mathrm{P}} \rho+c_{\mathrm{P}, \mathrm{l}} w\right)$, and $\Omega$ is the moisture storage capacity, defined as the slope of water retention curve $\left(\Omega=\partial w / \partial p_{\mathrm{C}}\right)$.

It is worth noting that after a few manipulations and rearrangements, the above Equations (5) and (6) can be written in the following matrix form:

$$
d_{\mathrm{a}}\left[\begin{array}{c}
\frac{\partial T}{\partial t} \\
\frac{\partial p_{\mathrm{C}}}{\partial t}
\end{array}\right]=\nabla\left(C \nabla\left[\begin{array}{l}
T \\
p_{\mathrm{C}}
\end{array}\right]\right)+\beta \nabla\left[\begin{array}{l}
T \\
p_{\mathrm{C}}
\end{array}\right]+\left[\begin{array}{l}
F_{\mathrm{h}} \\
F_{\mathrm{m}}
\end{array}\right]
$$

where damping $\left(d_{\mathrm{a}}\right)$, diffusion $(C)$ and convection $(\beta)$ matrices are respectively defined by:

$$
\begin{aligned}
& d_{\mathrm{a}}=\left[\begin{array}{ll}
C_{\mathrm{T}} & 0 \\
0 & \Omega
\end{array}\right] \\
& C=\left[\begin{array}{ll}
C_{11} & C_{12} \\
C_{21} & C_{22}
\end{array}\right]=\left[\begin{array}{ll}
\lambda+L_{\mathrm{V}} \delta_{\mathrm{P}} \phi p_{\mathrm{sat}}^{\prime} & -\frac{L_{\mathrm{V}} \delta_{\mathrm{P}} \phi p_{\mathrm{sat}}}{\rho_{\mathrm{l}} R_{\mathrm{V}} T} \\
-\delta_{\mathrm{P}} \phi p_{\mathrm{sat}}^{\prime} & K_{\mathrm{l}}+\frac{\delta_{\mathrm{P}} \phi p_{\mathrm{sat}}}{\rho_{\mathrm{l}} R_{\mathrm{V}} T}
\end{array}\right]
\end{aligned}
$$

$p_{\text {sat }}^{\prime}=\partial p_{\text {sat }} / \partial T$ being the derivative of saturation vapor pressure.

As for the matrix $\beta$, it can be expressed in the following form:

$$
\begin{aligned}
\beta & =v\left[\begin{array}{ll}
D_{11} & D_{12} \\
D_{21} & D_{22}
\end{array}\right] \\
& =v\left[\begin{array}{ll}
-\left(\rho_{\mathrm{a}} c_{\mathrm{P}, \mathrm{a}}+L_{\mathrm{V}} \frac{\partial \rho_{\mathrm{V}}}{\partial T}\right) & -\frac{L_{\mathrm{V}} \phi}{\rho_{\mathrm{l}} R_{\mathrm{V}} T} \frac{\partial \rho_{\mathrm{V}}}{\partial \phi} \\
\frac{\partial \rho_{\mathrm{V}}}{\partial T} & -\left(\frac{\phi}{\rho_{\mathrm{l}} R_{\mathrm{V}} T} \frac{\partial \rho_{\mathrm{V}}}{\partial \phi}\right)
\end{array}\right]
\end{aligned}
$$

To go further, the current model consists of converting, via MatLab, the measurable physical properties of the material such as $K_{1}, \phi, \delta_{\mathrm{P}}$ and $\lambda$ which depend on moisture content $w$ into partial differential equations (PDEs), $C_{11}, C_{12}, D_{11}, D_{12}, \Omega$ and $C_{\mathrm{T}}$ which are dependent on $p_{\mathrm{C}}$ and $T[27]$. This is schematically depicted in Figure 1. 


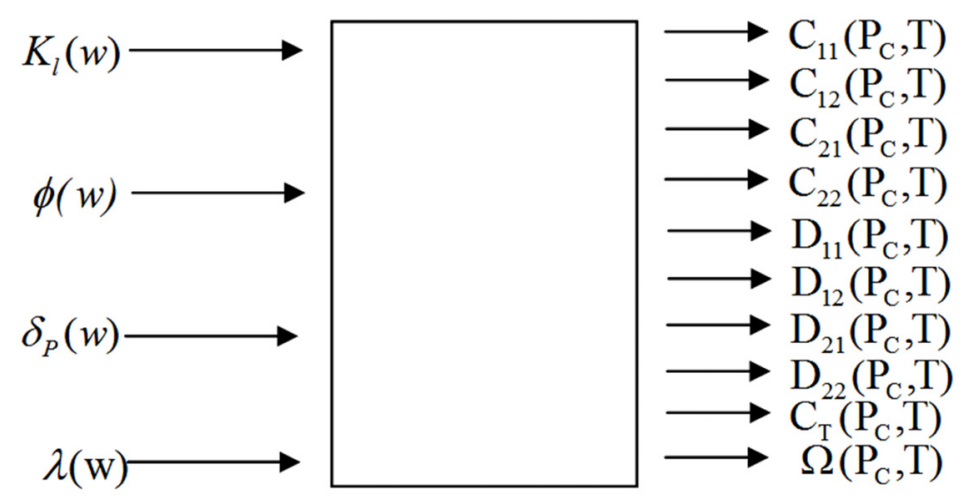

Fig. 1. Conversion of measurable material properties.

\section{Boundary conditions}

It goes without saying that any modeling and numerical simulation have to be backed by appropriate boundary conditions. In building envelope simulation, the boundary conditions and initial conditions, carefully selected and combined, greatly help to achieve good accuracy without resorting to the use of prohibitive computing times. In this framework, external boundary conditions of building envelopes belong to three main groups [10,28] that are moisture saturation, constant heat and moisture flow, and heat/moisture flow through surface resistance film fixed on external surface. Equations (11) and (12) provide the exterior boundary conditions based on Dirichlet assumptions. As for the internal surface of the wall, the temperature and pressure are maintained constant.

\subsection{Moisture boundary conditions}

The supply of moisture flux through the outside surface of the envelope, $g_{\mathrm{n}, \mathrm{e}}$, can be expressed using the following relationship:

$$
g_{\mathrm{n}, \mathrm{e}}=\beta_{\mathrm{P}, \mathrm{e}}\left(p_{\mathrm{v}, \mathrm{e}}-p_{\mathrm{surf}, \mathrm{e}}\right)+g_{\mathrm{wdr}}
$$

where $\beta_{\mathrm{P}, \mathrm{e}}$ is the vapor transfer coefficient of the exterior surface, $p_{\mathrm{v}, \mathrm{e}}$ is the water vapor pressure of the outdoor air, and $p_{\text {surf, e }}$ is the water vapor pressure on the exterior surface, $g_{\mathrm{wdr}}$ is the moisture supply due to wind-driven rain.

For the internal side of the wall, the moisture flux is obtained according to the following relationship:

$$
g_{\mathrm{n}, \mathrm{i}}=\beta_{\mathrm{P}, \mathrm{i}}\left(p_{\mathrm{v}, \mathrm{i}}-p_{\text {surf }, \mathrm{i}}\right)
$$

where $\beta_{\mathrm{P}, \mathrm{i}}$ is the vapor transfer coefficient of the interior surface, $p_{\mathrm{v}, \mathrm{i}}$ is the water vapor pressure of the indoor air and $p_{\text {surf,i }}$ is the water vapor pressure of the interior surface.

\subsection{Heat boundary conditions}

Heat flux through external surface includes conductive, convective and latent heat effects only. It can be expressed as:

$$
q_{\mathrm{n}, \mathrm{e}}=\alpha_{\mathrm{e}}\left(T^{e q}-T_{\mathrm{surf}, \mathrm{e}}\right)+L_{\mathrm{V}} \beta_{\mathrm{p}, \mathrm{e}}\left(p_{\mathrm{v}, \mathrm{e}}-p_{\text {surf }, \mathrm{e}}\right)
$$

where $\alpha_{\mathrm{e}}$ is the heat transfer coefficient of the exterior surface, $T^{e q}$ is the equivalent exterior temperature and $T_{\text {surf,e }}$ is the temperature of the exterior surface.

Likewise, heat flux through internal surface of the building envelope, $q_{\mathrm{n}, \mathrm{i}}$, is given by:

$$
q_{\mathrm{n}, \mathrm{i}}=\alpha_{\mathrm{i}}\left(T_{\mathrm{i}}-T_{\mathrm{surf}, \mathrm{i}}\right)+L_{\mathrm{V}} \beta_{\mathrm{p}, \mathrm{i}}\left(p_{\mathrm{v}, \mathrm{i}}-p_{\mathrm{surf}, \mathrm{i}}\right)
$$

where $\alpha_{\mathrm{i}}$ is the heat transfer coefficient of the interior surface, $T_{\mathrm{i}}$ is the temperature of the indoor air, and $T_{\mathrm{surf}, \mathrm{i}}$ is the temperature of the interior surface.

Noting that the wind speed in porous media is commonly expressed by the experimentally observed DarcyBoussinesq law.

$$
v=-\frac{k_{\mathrm{a}}}{\mu_{\mathrm{a}}}\left(\nabla p_{\mathrm{a}}+g \beta \rho_{\mathrm{a}}\left(T^{e q}-T_{0}\right)\right)
$$

where $k_{\mathrm{a}}$ is the air permeability of the material, $\mu_{\mathrm{a}}$ is air dynamic viscosity, $p_{\mathrm{a}}$ is the dry air pressure, $\beta=3.43 \times$ $10^{-3} \mathrm{~K}^{-1}$ is the thermal expansion coefficient of air, $g=$ $9.81\left(\mathrm{~m} . \mathrm{s}^{-2}\right)$ is the acceleration due to gravity, and $T_{0}$ is the reference temperature.

\section{Numerical handling and validation of the model}

\subsection{Model benchmarking}

As it has been stated above, the working of the aforementioned model equations has been checked considering a 1D benchmark exercise \#1. The latter arises from a series of benchmark cases from a work outcome of the EU-initiated project for standardization of heat, air and 


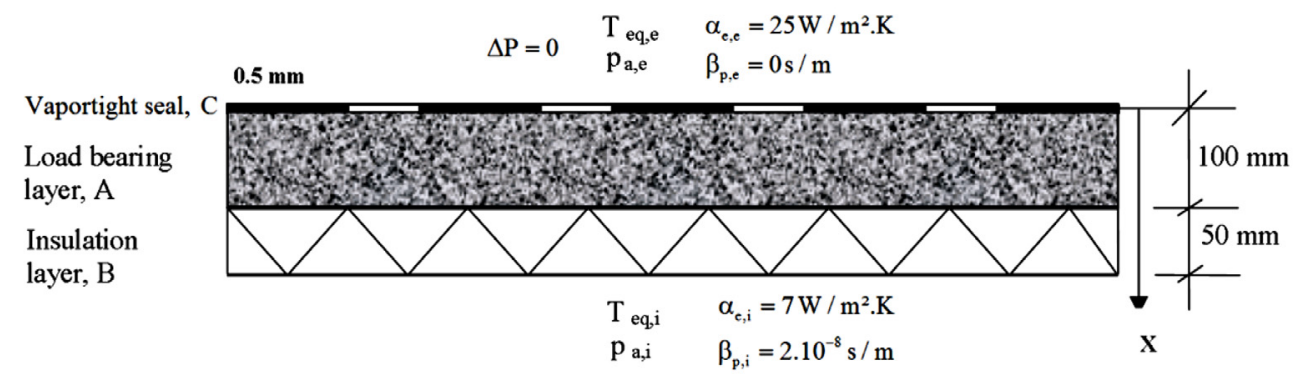

Fig. 2. Construction details for the analyzed benchmark case.

moisture calculation methods (European project known as HAMSTAD-WP2) [29,30]. The five exercises of this benchmark are suited to assess the performance and accuracy of hygrothermal model in one dimensional configuration. In this project, Hagentoft et al. [30] developed a model in which they considered the temperature and the capillary suction pressure as potentials for the energy conservation and the moisture transport, respectively.

The benchmark exercise whose schematic is given in Figure 1 deals with interstitial condensation occurring at the contact surface between two materials. The construction, from lowest $x$-coordinate (external side) to the highest, is built up as follows; vapor tight seal, $100 \mathrm{~mm}$ load bearing material and $50 \mathrm{~mm}$ thermal insulation as shown in Figure 2. The materials have different thermal and moisture properties: the load bearing material is capillary active, while the insulation is hygroscopic but capillary non-active (infinite resistance to liquid flow), and thermal conductivities differ by a factor 50 (at dry conditions). The structure is perfectly airtight. Note that other benchmarking exercises exist and these are reported in Tariku [31].

\subsubsection{Material property functions}

Material properties in term of moisture content $w$ are given in Table 1 for both bearing layer and insulation, respectively. Some thermo-physical specifications of materials are presented in Table 2 .

\subsubsection{Initial conditions}

The following initial conditions were adopted:

- For load bearing material: $w=145 \mathrm{~kg} \cdot \mathrm{m}^{-3}, T=$ $283 \mathrm{~K}$.

- For insulation: $w=0.065 \mathrm{~kg} \cdot \mathrm{m}^{-3}, T=283 \mathrm{~K}$.

\subsubsection{Boundary conditions}

The boundary conditions corresponding to the considered problem are as follows:

- For heat and moisture, a data file supplies the hourly values for a period lasting over one year. For intermediate values of time, they are obtained by interpolation.
- The outside equivalent temperatures encompass both the temperatures of the ambient air and that of the radiation.

- No difference in pressure is considered.

The surface transfer coefficients are given by:

$$
\begin{aligned}
& \alpha_{\mathrm{e}, \mathrm{e}}=25 \mathrm{~W} \cdot \mathrm{m}^{-2} \cdot \mathrm{K}^{-1}, \alpha_{\mathrm{e}, \mathrm{i}}=7 \mathrm{~W} \cdot \mathrm{m}^{-2} \cdot \mathrm{K}^{-1}, \\
& \beta_{\mathrm{p}, \mathrm{e}}=0 \mathrm{~s} \cdot \mathrm{m}^{-1}, \beta_{\mathrm{p}, \mathrm{i}}=2 \times 10^{-8} \mathrm{~s} \cdot \mathrm{m}^{-1}
\end{aligned}
$$

Note that these conditions allow a very good case for checking the heat and moisture transfer model.

As cited above, the numerical simulation has been performed using the COMSOL Multiphysics [24], and the required results are the following ones:

- Capillary pressure $p_{\mathrm{c}}$ in space and time for load bearing element A, and insulation B as shown in Figure 2.

- Temperature $T(x, t)$.

- Total moisture weight $M$ in each layer.

- Heat flux $q$ crossing the structure from interior to the wall.

The model simulates, for over a period of one year, the distributions of the capillary pressure $p_{\mathrm{C}}$ and the temperature $T$. In Figure 3, the temperature distribution in load bearing element and insulation is depicted.

\subsection{Discretisation, meshing and solver default settings}

Needing to be able to use meshes that smoothly change in size near the two layers internal interface, where the solution is expected to change abruptly, a regular 157node mesh has been applied producing 216 triangular elements as shown in Figure 4.

For spatial discretisation, the system of partial differential equations (PDE) is transformed by COMSOL solver into a set of ordinary differential equations (ODE) through spatial discretisation. The Finite Volume Method (FVM) is used and the computational domain is subdivided in a number of finite elements resulting in discrete balance equations for all elements. The flux terms are discretised by using central difference approximations for the diffusion terms and upwinding schemes for the convective terms.

With all spatial gradients replaced with finite difference approximations of the transient heat and moisture balance equations, an ordinary differential equation system $(\mathrm{ODE})$ is obtained. In the current version 
M. Maliki et al.: Mechanics \& Industry 16, 509 (2015)

Table 1. Material properties in term of moisture content.

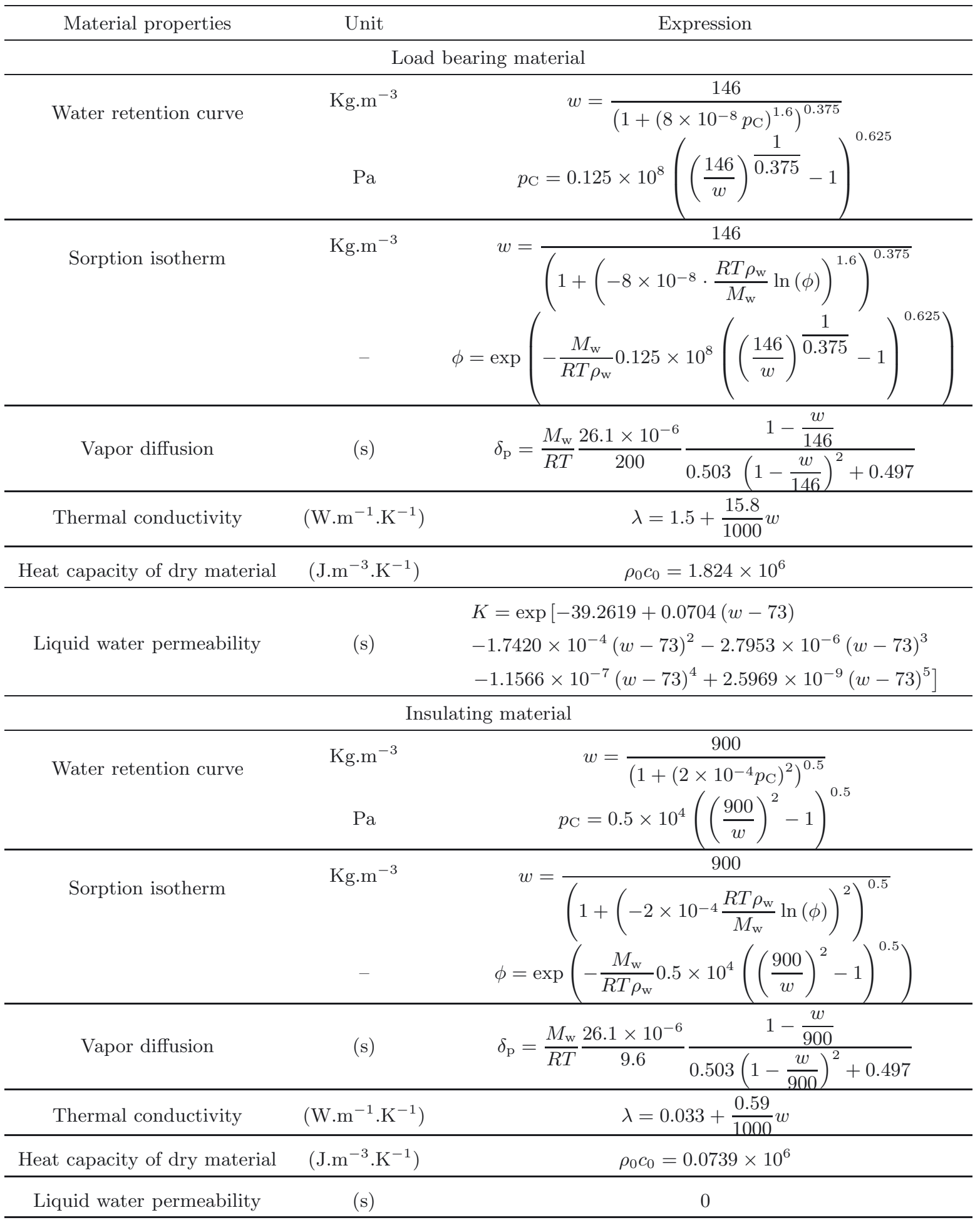

Table 2. Some genaral data of used materials.

\begin{tabular}{cccc}
\hline Thermo-physical parameter & Symbol & Unit & Value \\
\hline Liquid water density & $\rho_{\mathrm{w}}$ & $\mathrm{kg} \cdot \mathrm{m}^{-3}$ & 1000 \\
Gas constant for water vapor & $R$ & $\mathrm{~J} \cdot \mathrm{mol}^{-1} \cdot \mathrm{K}$ & 8.314 \\
Molar mass of water vapor & $M_{\mathrm{w}}$ & $\mathrm{kg} \cdot \mathrm{mol}^{-1}$ & 0.018 \\
Enthalpy of evaporation & $L_{\mathrm{V}}$ & $\mathrm{J} \cdot \mathrm{kg}^{-1}$ & $2.5 \times 10^{6}$ \\
\hline
\end{tabular}




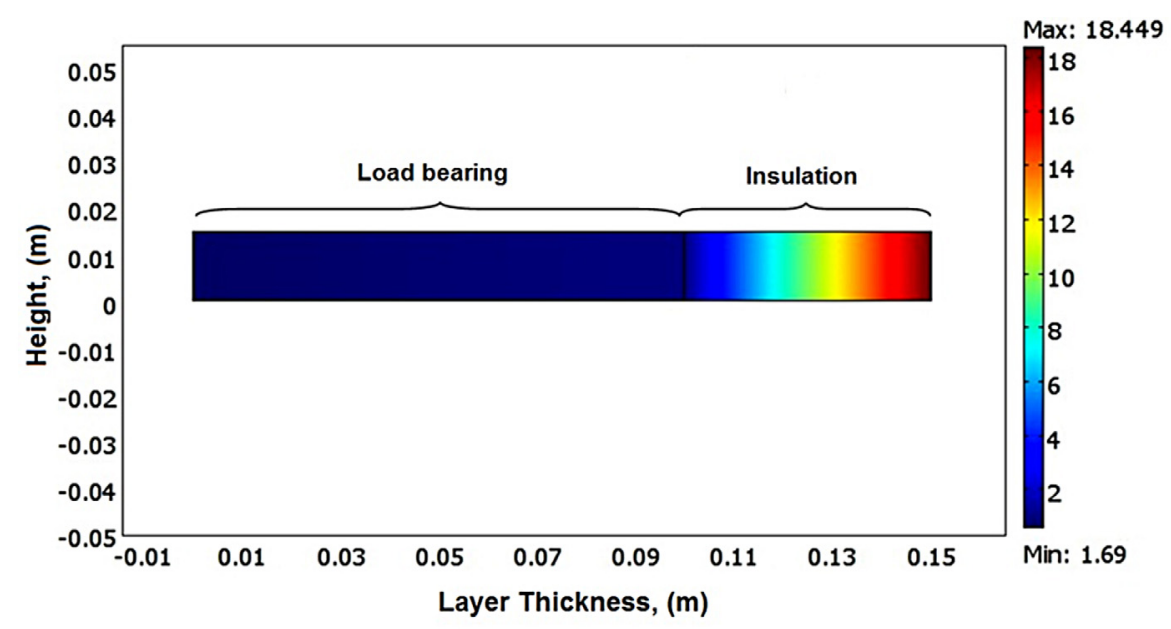

Fig. 3. Temperature's distribution in the wall after 20 days $\left({ }^{\circ} \mathrm{C}\right)$.

Load Bearing

Insulation

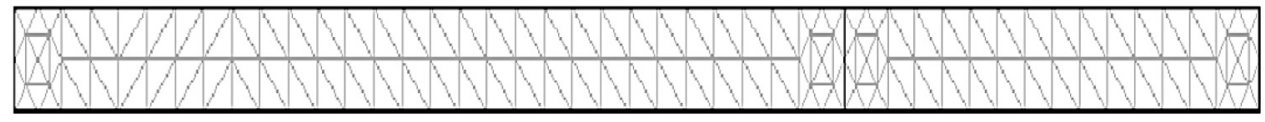

Fig. 4. Mesh generation for the analyzed insulated roof.

of COMSOL, this system of combined heat and moisture transport is solved using a Newton-Raphson iteration method implemented in the generic ODE-solver. The implementation of this generic multi-step solver in the COMSOL framework is extensively documented in Reference [32]. However, since the air mass balance equation is simplified to a steady state formulation, its discretised form cannot be included in the general form of the obtained ordinary differential equation. Therefore, this set of linear equations is solved separately from the coupled transient heat and moisture transport. In this respect, the quasi-steady state implementations means that during integration of the coupled energy and moisture balance equations the air flow field is kept constant. At defined time intervals, a new steady state solution of the air flow field is calculated and used during the continued integration of heat and moisture balances.

\subsection{Results and discussion}

\subsubsection{Moisture transport}

Using properties of the material, the total moisture content can be easily computed from the distribution of capillary pressure $p_{\mathrm{C}}$. Figure 5 shows the total moisture content in load bearing during the first year. As a result of the low value in average external temperature $\left(-3,1^{\circ} \mathrm{C}\right)$ in winter period and the convection implying mass displacement front towards the lower air pressure, an important moisture content increase is observed. Conversely, dry conditions occurring between 2500 and $6500 \mathrm{~h}$ and weak convection effect causing abrupt drying of the material. High discrepancies between internal and external pressure coupled to temperature drop are observed during the last quarter of the simulation period, this lead to a new increasing in moisture content levels. Here we see the comparison between the results of the current model and that resulting from HAMSTAD test. It can be seen from this figure that the predicted profile generally corroborates, over the considered period, HAMSTAD's results with a maximum error of $1.25 \%$ and an average difference in total moisture content evaluated to $0.75 \%$ only. This allows us to state that the current model is globally able to reproduce available results in literature.

\subsubsection{Heat transport}

Heat flow crossing the structure from the inside during the first $500 \mathrm{~h}$ obtained with the current model in comparison with HAMSTAD test is displayed in Figure 6. It is observed that our prediction is very close to that of the test case. The graph tendency of heat flux depends on the period of the day; the quantity of energy crossing the wall is conversely proportional to outside temperature. Indeed, an ascending tendency corresponds to the period of the day included between $3 \mathrm{pm}$ and 8 am when the average temperature is globally negative with a maximum outgoing flux reached at about $8 \mathrm{am}$. The downward parts of the graph represent the flux behavior during the rest of the day where the average temperature is globally positive, the lowest heat flux value is registered at $3 \mathrm{pm}$.

To investigate energy distribution within the studied structure, we depict in Figure 7 the temperature variation 


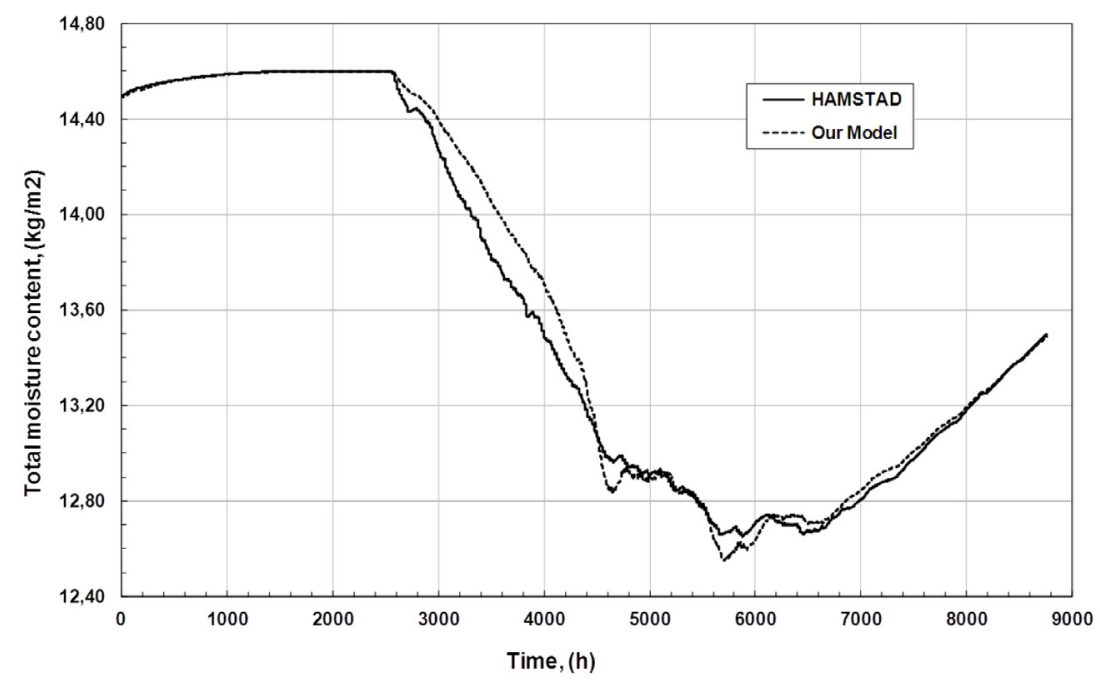

Fig. 5. Time-dependent change of total moisture content in load bearing during the first year.

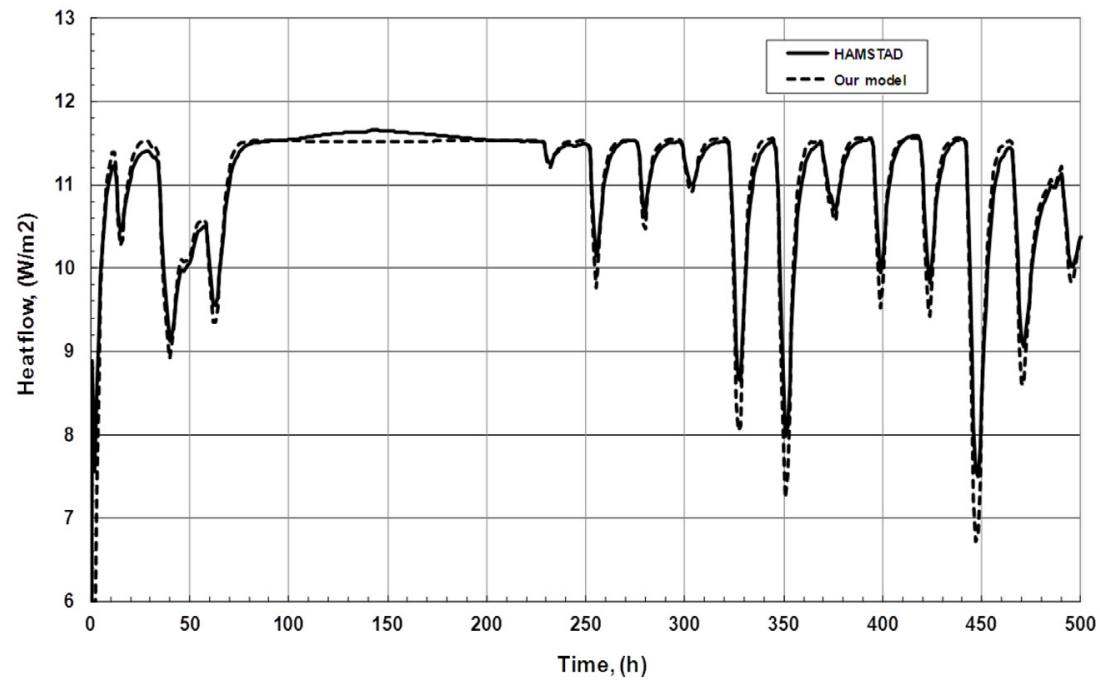

Fig. 6. Time-dependent change of heat flux from interior to the wall.

through both layers during the first three days $(24 \mathrm{~h}, 48 \mathrm{~h}$ and $72 \mathrm{~h}$ ) of the simulation, measures show that the temperature gradient is maximum in the insulating material which the regulating effect of heat is strongly proved. The temperature within the load bearing remains quasi constant, this is due to the very high thermal conductivity of the material, the gradient of temperature calculated in the insulating material is about one hundred times superior to in the load bearing.

In Figure 8, temperature evolution profile during the first $72 \mathrm{~h}$ at different positions of the multilayered structure is shown. The three curves at the bottom of the graph expressing temperature fluctuations at three different points of the load bearing layer are almost similar. The high conduction and convection of the material makes the temperature remaining almost constant. This also explains the vertiginous fall of temperature during the first ten hours, passing from $283 \mathrm{~K}$ (initial temper- ature of the structure) to about $274 \mathrm{~K}$ (outside ambient temperature). The thermal behaviour of the load bearing follows the outside ambient temperature variations.

The temperature in the middle of the insulating material represents approximately half of the temperature difference between the inside and outside surfaces. The used insulating material insures after half an hour, for the inside surface, a relatively constant temperature bordering the internal ambient temperature (293 K).

\section{Conclusion}

The present study numerically investigates the coupled heat and moisture transport in porous buildings materials. The model considers the capillary pressure and the temperature gradients as driving potentials of the 


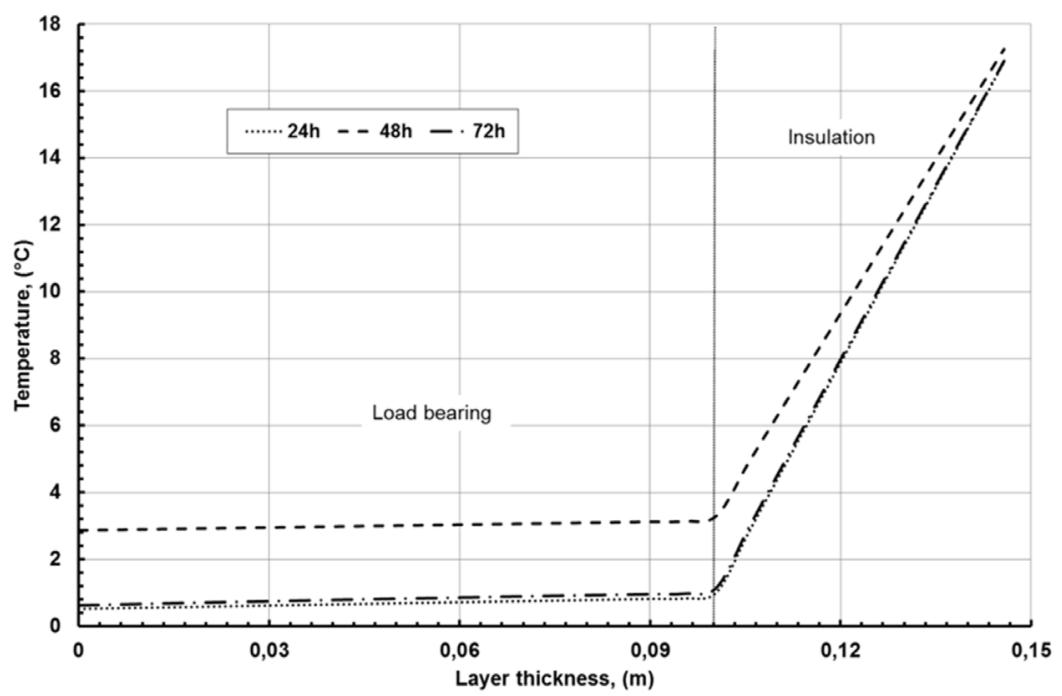

Fig. 7. Temperature's distribution through both layers during $24 \mathrm{~h}, 48 \mathrm{~h}$ and $72 \mathrm{~h}$.

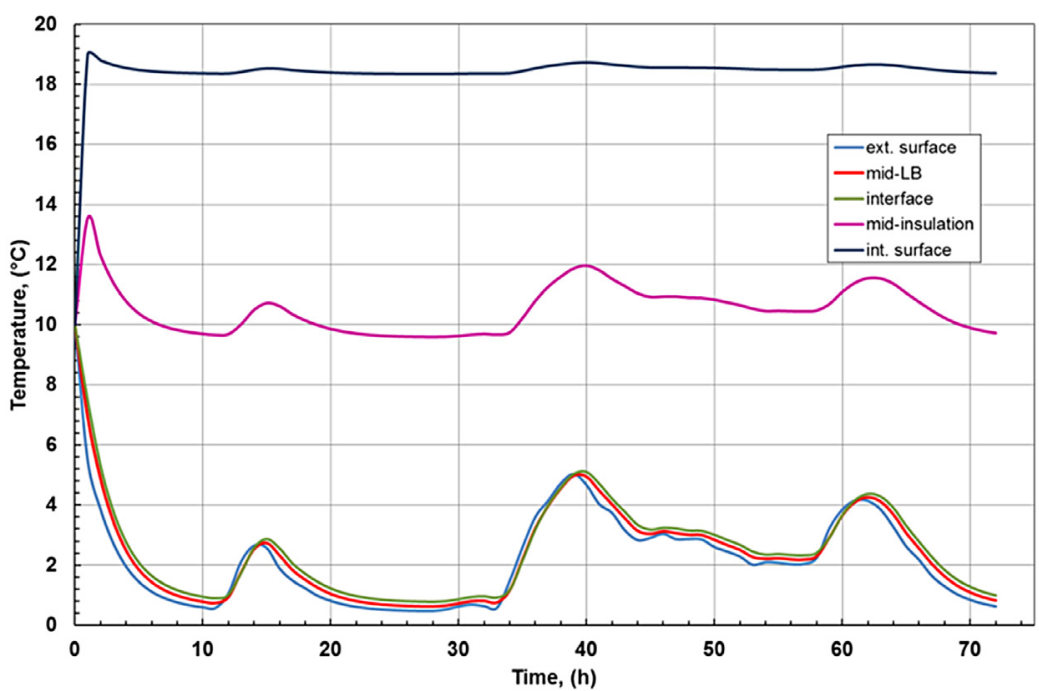

Fig. 8. Time-dependent change of temperature evolution at different positions.

coupled heat and moisture transfer through porous materials of building envelope. Such a model has been successfully benchmarked against a one-dimensional numerical test case. The governing partial-differential equations (PDEs) of the three transport phenomena are coupled and solved simultaneously for temperature and capillary pressure considered as driving potentials. The model accommodates non-linear transfer and storage properties of materials, moisture transfer by vapor diffusion, capillary liquid water transport and convective heat and moisture transfer through multi-layered porous media. The PDEs are derived in such a way that each PDE is described with a single driving potential, which is continuous across the interfaces of adjoining materials.

The COMSOL-Multiphysics solver has been chosen to solve the governing equations of HAM transport. The good agreement obtained with the considered benchmarks evidences the potential of the present model, and suggests that its development and implementation are promising, and thus, it can be further coupled with an indoor model to create a whole building hygrothermal model, to take into account the multi-dimensional heat, air and moisture transfer. The new approach borrowed here provides a reliable and efficient model for simulating the coupled heat, air and moisture transfer through multilayer building materials.

\section{References}

[1] M. Charde, R. Gupta, Annual Thermal Performance of a Hollow Roof in Combination with a Cavity Wall and Static Sunshade: Experimental Study of Energy-Efficient Rooms, J. Energy Eng. 139 (2013) 281-289 
[2] M.W. Lin, J.B. Berman, Modelling of moisture migration in an FRP reinforced masonry structure, Building Environement 41 (2006) 646-656

[3] S.O. Olutimayin, C.J. Simonson, Measuring and modeling vapor boundary layer growth during transient diffusion heat and moisture transfer in cellulose insulation, Int. J. Heat Mass Transfer 48 (2005) 3319-3330

[4] D.B. Ingham, I. Pop, Transport Phenomena in Porous Media, Elsevier, Oxford, 2005

[5] H.S.F. Awadalla, A.F. El-Dib, M.A. Mohamad, Mathematical modelling and experimental verification of wood drying process, Energy Convers. Manag. 45 (2004) 197-207

[6] O.F. Osanyintola, C.J. Simonson, Moisture buffering capacity of hygroscopic building materials: experimental facilities and energy impact, Energy Builings 38 (2006) 1270-1282

[7] N. Mendes, P.C. Philippi, A method for predicting heat and moisture transfer through multilayered walls based on temperature and moisture contents gradients, Int. J. Heat Mass Transfer 48 (2005) 37-51

[8] J.R. Philip, D.A. De Vries, Moisture movement in porous materials under temperature gradients, Transactions American Geophysical Union 38 (1957) 222-232

[9] A.V. Luikov, Heat and Mass Transfer in Capillary porous Bodies (Chap. 6), Pergamon Press, Oxford, UK, 1966

[10] N. Mendes, P.C. Philippi, R. Lamberts, A new mathematical method to solve highly coupled equations of heat and mass transfer in porous media, Int. J. Heat Mass Transfer 45 (2002) 509-518

[11] G.H. dos Santos, N. Mendes, Unsteady combined heat and moisture transfer in unsaturated porous soils, J. Porous Media 8 (2005) 493-510

[12] G.H. dos Santos, N. Mendes, Heat, air and moisture transfer through hollow porous blocks, Int. J. Heat Mass Transfer 52 (2009) 2390-2398

[13] C.R. Pedersen, Prediction of moisture transfer in building constructions, Building Environement 27 (1992) 387-397

[14] H.M. Kunzel, K. Kiessel, Calculation of heat and moisture transfer in exposed building components, Int. J. Heat Mass Transfer 40 (1997) 159-167

[15] A. Kalagasidis, HAM-Tools: An Integrated Simulation Tool for Heat, Air and Moisture Transfer Analysis in Building Physics, Ph.D. thesis, Chalmers University of Technology, Sweden, 2004

[16] L. Qinru, R. Jiwu, F. Paul, Development of HAM tool for building envelope analysis, Building Environement 44 (2009) 1065-1073

[17] M. Qin, R. Belarbi, A. Aït-Mokhtar, L.O. Nilsson, Coupled heat and moisture transfer in multi-layer building materials, Construction and Building Materials 23 (2009) 967-975

[18] M. Qin, A. Aït-Mokhtar, R. Belarbi, Two-dimensional hygrothermal transfer in porous building materials, Appl. Thermal Eng. 30 (2010) 2555-2562
[19] K. Fanhong, W. Huaizhu, Heat and mass coupled transfer combined with freezing process in building materials: Modeling and experimental verification, Energy and Buildings 43 (2011) 2850-2859

[20] N.M.M. Ramos, A.S. Kalagasidis, V.P. de Freitas, J.M.P.Q. Delgado, Numerical simulation of transient moisture transport for hygroscopic inertia assessment, J. Porous Media 15 (2012) 793-804

[21] B. Klemczak, Prediction of Coupled Heat and Moisture Transfer in Early-Age Massive Concrete Structures, Numer. Heat Transfer A 60 (2011) 212-233

[22] L. Yanfeng, W. Yingying, W. Dengjia, L. Jiaping, Effect of moisture transfer on internal surface temperature, Energy Buildings 60 (2013) 83-91

[23] F. Tariku, M.K. Kumaran, P. Fazio, Transient model for coupled heat, air and moisture transfer through multilayered porous media, Int. J. Heat Mass Transfer 53 (2010) 3035-3044

[24] COMSOL, Multiphysics Modeling and Simulation Software, http://www. comsol.com, 2011

[25] J. Carmeliet, H. Hens, S. Roels, O. Adan, H. Brocken, R. Cerny, Z. Pavlik, C. Hall, K. Kumaran, L. Pel, Determination of the liquid water diffusivity from transient moisture transfer experiments, J. Thermal Env. Build. Sci. 27 (2004) 277-305

[26] H.R. Thomas, H. Missoum, Three-dimensional coupled heat, moisture, and air transfer in a deformable unsaturated soil, Int. J. Numer. Methods Eng. 44 (1999) 919-943

[27] A.W.M. van Schijndel, Integrated Heat Air and Moisture Modeling and Simulation, Ph.D. thesis, Eindhoven University, Eindhoven, Netherlands, 2007

[28] H.M. Kunzel, Simultaneous heat and moisture transport in building components: one and two-dimensional calculation using simple parameters, Ph.D. thesis, Institute of Building Physics, Germany, 1995

[29] C.E. Hagentoft, HAMSTAD - Final report: Methodology of HAM-modeling. Rep. R-02:8, Gothenburg, Department of Building Physics, Chalmers University of Technology, 2002

[30] C.E. Hagentoft, A. Kalagasidis, B. Adl-Zarrabi, S. Roels, J. Carmeliet, H. Hens, J. Grunewald, M. Funk, R. Becker, D. Shamir, O. Adan, H. Brocken, K. Kumaran, R. Djebbar, Assessment Method of Numerical Prediction Models for Combined Heat, Air and Moisture Transfer in Building Components: Benchmarks for One-dimensional Cases, J. Thermal Env. Build. Sci. 27 (2004) 327-352

[31] F. Tariku, Whole building heat and moisture analysis, Ph.D. thesis, Concordia University, Montreal, Canada, 2008

[32] A. Nicolai, Modelling and numerical simulation of salt transport and phase transitions in unsaturated porous building materials, PhD. dissertation, Syracuse University, New York, 2007 